\title{
Normalisation of refractive error after steroid injection for adnexal haemangiomas
}

\author{
Andrew J Morrell, Harry E Willshaw
}

\begin{abstract}
A longitudinal study of 27 patients with infantile haemangiomas is reported. It confirmed the efficacy of local steroid injection as a method of treatment; $81.5 \%$ of patients showed a marked improvement, with the lesion reducing to $25 \%$ or less of its original size. Involution was most marked in the first two weeks but continued for up to four months after injection. Amblyopia was present in $43 \%$ of children and was usually the result of induced refractive error rather than obstruction of the visual axis or strabismus. Anisometropia was found in $68 \%$ of children, with a high incidence of asymmetric astigmatism on the side of the haemangioma. Following local steroid injection a marked reduction in astigmatism was noted in $53.8 \%$ of children, a lesser reduction in $\mathbf{1 5 . 4 \%}$, and no reduction in $\mathbf{3 0 . 8 \%}$. Successful treatment of the haemangioma, therefore, may not remove the risk of amblyopia, and regular refraction and visual assessment remain mandatory.
\end{abstract}

Infantile haemangiomas affect between $3 \%^{1}$ and $8 \%{ }^{2}$ of the population. They have a predilection for the face and commonly appear within the first two months of life. There is a phase of rapid enlargement over the first four to eight months, followed by a period of stability and subsequent spontaneous involution, with $70 \%$ having regressed by seven years of age.

In addition to the cosmetic blemish $43-60 \%$ of children with adnexal haemangiomas will develop strabismic, anisometropic, or deprivation amblyopia. A smaller number will develop other ocular complications including exophthalmos, exposure keratitis, or optic atrophy. ${ }^{45}$ Previous studies in this unit have shown that the majority of cases of amblyopia result from anisometropia rather than strabismus or occlusion of the visual axis. ${ }^{6}$ Robb $^{7}$ also found a $46 \%$ incidence of asymmetric refractive error in affected children.

Several methods of treatment (including surgical excision, cryotherapy, irradiation, and injection of sclerosing agents) have been used for infantile haemangiomas, but all have a risk of local or systemic complications. ${ }^{8}$ Similarly, though effective, systemic steroids may adversely affect the child's growth, and therefore intralesional steroid injections were introduced in the late 1970s. These have been shown to promote rapid resolution of the haemangioma, ${ }^{9 \cdot 12}$ but the natural history of the refractive error following treatment has not been explored (though Kushner $^{11}$ noted reversal of refractive error in one child following early treatment).

Since December 1981 we have treated 27 children with adnexal haemangiomas by means of local steroids. We report the results of treatment in this group with respect to resolution of the lesion, the effect on refractive error, and the long term visual outcome.

\section{Patients and methods}

The diagnosis of haemangioma was based on the clinical appearance of either a raised, red, dimpled lesion involving the superficial skin, or a 'subcutaneous' swelling or fullness with a dark reddish blue discolouration, together with a history of onset, growth, and tendency of the lesion to increase in size when the patient cried.

All children were examined for evidence of haemangiomas in other sites, and a CT scan was performed to define the limits of the adnexal haemangioma where extension into the orbit was suspected. Two patients required biopsy to establish the diagnosis because of clinical suspicion of an underlying rhabdomyosarcoma.

The haemangiomas were measured and photographed immediately before injection and at least once after injection. The size was noted and the position recorded by the same notation as employed in spectacle trial frames. For example, a lesion extending from the $60^{\circ}$ axis to the $150^{\circ}$ axis was considered to have a $90^{\circ}$ extent. Cycloplegic refraction (by streak retinoscopy after the instillation of cyclopentolate $1 \%$ ) and fundal examination were performed prior to injection in 25 of the children, the remaining two having haemangiomas remote from the eyelids. Refraction and fundal examination were repeated at intervals after injection.

Indications for treatment of adnexal haemangiomas were as Kushner ${ }^{13}$ advised: occlusion of the visual axis, strabismus, an asymmetric refractive error sufficient to cause amblyopia, or the tumour enlarging and showing the potential for the above problems. Intralesion injections of steroids were undertaken under general anaesthetic, a combination of triamcinolone (20$40 \mathrm{mg}$ ) and dexamethasone (4 mg) being given. In one early case methylprednisolone $(40 \mathrm{mg}$ ) was used in place of dexamethasone. In the first five cases the steroid was injected round the margins of the lesion; thereafter injections were

Table 2 Ophthalmic sequelae in children with an adnexal haemangioma and amblyopia

\begin{tabular}{ll}
\hline Complication & No. of patients \\
\hline $\begin{array}{l}\text { Asymmetric astigmatic error }>0 \cdot 75 \mathrm{D} \\
\text { Asymmetric astigmatic error }+\end{array}$ & 7 \\
$\begin{array}{l}\text { strabismus } \\
\text { Asymmetric astigmatic error }+ \text { lid }\end{array}$ & 1 \\
$\begin{array}{l}\text { occlusion } \\
\text { Asymmetric anisometropia - } \\
\text { hypermetropia }\end{array}$ & 1 \\
\hline
\end{tabular}

\begin{tabular}{lc} 
response & No. of patients \\
\hline 0 & 2 \\
1 & 2 \\
2 & 1 \\
3 & 10 \\
4 & 12 \\
Total & 27 \\
\hline
\end{tabular}


given directly into the lesion at multiple sites to minimise the possibility of subcutaneous fat atrophy following treatment. Care was taken to avoid direct injection into the vascular channels. If resolution of the haemangioma was incomplete, a further injection was carried out between six weeks and eight months after the first.

The response to treatment was graded from 0 to 4 :

$\begin{array}{llll}0 & \text { representing }<25 \% & \text { resolution } \\ 1 & \text { representing } \geqslant 25 \%<50 \% & \text { resolution } \\ 2 & \text { representing } \geqslant 50 \%<75 \% & \text { resolution } \\ 3 & \text { representing } \geqslant 75 \%<100 \% & \text { resolution } \\ 4 & \text { representing } 100 \% & \text { resolution }\end{array}$

Where possible monocular visual acuities were obtained before injection and at subsequent post-injection visits. Methods appropriate for age were used, including the acuity card procedure $^{14}$ in some infants.

\section{Results}

Of the 27 children treated 19 were female and eight male. Fifteen lesions involved the upper lid, eight the lower lid, and two both the upper and lower lids. One haemangioma was located over the left parotid gland and one on the upper lip.

The age at treatment ranged from 3 months to 34 months (mean 10.6 months), with the exception of one patient who was treated at 14 years of age. Twenty patients were under the age of 12 months at the time of first injection. Follow-up ranged from six months to 73 months (mean 24. 1 months). One child showed a grade 2 response two weeks after injection, but died of a streptococcal pneumonia three weeks after injection; there was no evidence at the time of any systemic effect of the steroids on this child and in particular no evidence of immune suppression.

Sixteen of the 27 patients received a second injection because of incomplete resolution of the haemangioma, the time interval between injections ranging from six weeks to eight months. Two patients received a third injection before achieving satisfactory resolution, and one patient received four injections but showed a grade 0 response. Involution was most marked in the first two weeks and continued for up to four months after injection.

\section{RESOLUTION OF HAEMANGIOMA}

Table 1 summarises the response of the patients to injection. Twenty two patients showed a grade 3 or 4 response, three patients showed a grade 1 or 2 response, and two patients showed a grade 0 response. Of the children showing no response to treatment one was aged 3 months and the other 14 years at the time of first injection.

Table 3 Asymmetric astigmatism related to the site of the haemangioma

\begin{tabular}{lll}
\hline Site of haemangioma & $\begin{array}{l}\text { No. patients with asymmetric } \\
\text { astigmatism }\end{array}$ & $\begin{array}{l}\text { No. patients without asymmetric } \\
\text { astigmatism }\end{array}$ \\
\hline Upper lid & 12 & 2 \\
Lower lid & 1 & 5 \\
Combined upper + lower lid & 2 & 0 \\
\hline
\end{tabular}

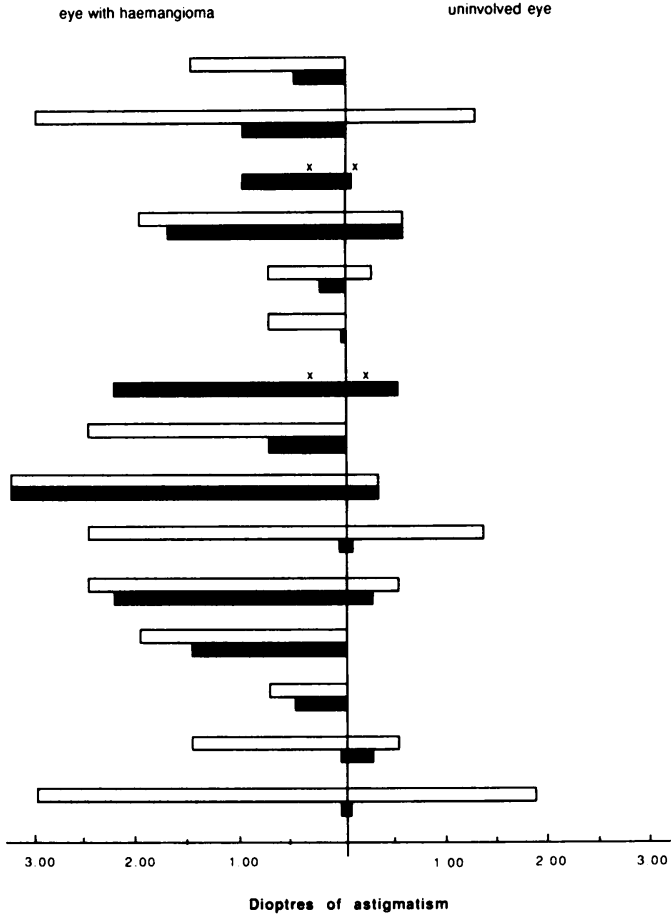

Figure 1 Astigmatic errors in children with infantile haemangiomas. Each pair of bars represents the astigmatism of one eye of each patient. White bars: preinjection. Black bars: postinjection. $\times=$ data unavailable.

Following injection one child developed an area of subcutaneous fat atrophy which resolved over a period of six months. This child was one of the first five to receive treatment, and steroid had been injected round the margins of the lesion. To minimise the possibility of this complication subsequent injections were given directly into the haemangioma at multiple sites, with no evidence of subcutaneous fat atrophy in the following 22 children.

A second girl developed an abscess at the site of injection, though this occurred three weeks after injection and followed a direct blow to the lid. One child showed an unusual response with apparent complete resolution of the haemangioma within four weeks of injection, but with recurrence of the lesion which then remained at one-quarter of its original size despite two further injections.

\section{VISUAL OUTCOME}

Two of the 27 patients were treated for non-sight threatening lesions and two were lost to followup before accurate monocular acuities were obtained. Of the remaining 23 patients $10(43 \%)$ developed amblyopia, all on the side of the haemangioma, with amblyopia defined as two or more lines of Snellen acuity less than the preferred eye. With the exception of one child who presented at the age of 14 years these children are still receiving amblyopia therapy.

By Jampolsky's criteria for significant anisometropia $^{15}$ all 10 children had significant asymmetric refractive error (Table 2 ). Seven had astigmatism alone, one astigmatism and strabismus, one astigmatism combined with lid closure, and one anisohypermetropia.

Of the 25 patients with lid involvement refractive data were not available for one child 
Table 4 Astigmatism associated with adnexal haemangiomas

\begin{tabular}{|c|c|c|c|c|c|c|c|c|}
\hline Case & $\begin{array}{l}\text { Position of the } \\
\text { haemangioma in } \\
\text { relation to the } \\
\text { limbus (degrees) }\end{array}$ & $\begin{array}{l}\text { Initial size of } \\
\text { haemangioma. } \\
\text { height } \times \text { width }(\mathrm{cm})\end{array}$ & $\begin{array}{l}\text { Refractive error of } \\
\text { involved eye before } \\
\text { injection }\end{array}$ & $\begin{array}{l}\text { Final refractive error } \\
\text { of involved eve after } \\
\text { injection }\end{array}$ & $\begin{array}{l}\text { Age at first } \\
\text { injection (months) }\end{array}$ & $\begin{array}{l}\text { Number of } \\
\text { injections } \\
\text { received }\end{array}$ & $\begin{array}{l}\text { Length of follow- } \\
\text { up (months) }\end{array}$ & $\begin{array}{l}\text { Ophthalmic } \\
\text { sequelae }\end{array}$ \\
\hline $\begin{array}{l}1 \\
2 \\
3 \\
4 \\
5 \\
6 \\
7 \\
8 \\
9\end{array}$ & $\begin{array}{r}90-150 \\
240-90 \\
80-180 \\
305-360 \\
90-150 \\
90-180 \\
50-160 \\
0-180 \\
25-130\end{array}$ & $\begin{array}{l}2.5 \times 3.25 \\
4.50 \times 4.75 \\
3.25 \times 1.5 \\
2.5 \times 2.25 \\
3.0 \times 2.0 \\
2.5 \times 2.5 \\
3.25 \times 2.0 \\
3.5 \times 3.0 \\
4.75 \times 3.25\end{array}$ & $\begin{array}{l}-1.00 /+3.00 \times 110 \\
+3.50 /+1.50 \times 155 \\
-0.25 /+0.75 \times 180 \\
-0.50 /+2.00 \times 180 \\
-2 \cdot 00 /+2.50 \times 120 \\
+1.50 /+2.50 \times 125 \\
-2.00 /+3.25 \times 120 \\
+1.50 /+2.50 \times 125 \\
\star\end{array}$ & $\begin{array}{l}+1.50 \mathrm{sph} \\
+2 \cdot 00 \mathrm{sph} \\
-0.75 /+0.50 \times 180 \\
0.00 /+1 \cdot 50 \times 180 \\
-0.75 /+2.25 \times 120 \\
+0.75 \mathrm{sph} \\
-2 \cdot 00 /+3.25 \times 117 \\
+1.25 /+0.75 \times 175 \\
+0.25 /+2.25 \times 90\end{array}$ & $\begin{array}{c}6 \\
15 \\
3 \\
3 \\
12 \\
5 \\
14 \mathrm{yr} \\
5 \\
6\end{array}$ & $\begin{array}{l}2 \\
2 \\
1 \\
2 \\
2 \\
2 \\
3 \\
2 \\
1\end{array}$ & $\begin{array}{r}6 \\
46 \\
18 \\
12 \\
21 \\
24 \\
31 \\
10 \\
29\end{array}$ & \multirow{3}{*}{$\begin{array}{l}\text { Amblyopia } \\
\text { Normal vision } \\
\text { Amblyopia } \\
\text { Normal vision } \\
\text { Amblyopia } \\
\text { Normal vision } \\
\text { Amblyopia } \\
\text { Normal vision } \\
\text { Amblyopia + } \\
\text { lid occlusion } \\
\text { Normal vision } \\
\text { Amblyopia } \\
\text { Amblyopia + } \\
\text { strabismus } \\
\text { Amblyopia } \\
\text { Amblyopia } \\
\text { Normal vision }\end{array}$} \\
\hline $\begin{array}{l}10 \\
11 \\
12\end{array}$ & $\begin{array}{r}20-90 \\
320-240 \\
80-140\end{array}$ & $\begin{array}{l}2.25 \times 2.0 \\
7.25 \times 6.5 \\
2.0 \times 1.25\end{array}$ & $\begin{array}{l}+0.50 /+0.75 \times 120 \\
+0.25 /+0.75 \times 80 \\
+5.00 /+2.00 \times 90\end{array}$ & $\begin{array}{l}+0.75 \mathrm{sph} \\
+0.00 /+0.25 \times 80 \\
+2.75 /+1.75 \times 95\end{array}$ & $\begin{array}{r}6 \\
6 \\
16\end{array}$ & $\begin{array}{l}1 \\
2 \\
1\end{array}$ & $\begin{array}{l}13 \\
10 \\
19\end{array}$ & \\
\hline $\begin{array}{l}13 \\
14 \\
15\end{array}$ & $\begin{array}{c}315-35 \\
20-160 \\
80-120\end{array}$ & $\begin{array}{l}3.75 \times 2.75 \\
3.0 \times 1.25 \\
2.5 \times 1.5\end{array}$ & $\begin{array}{l}\star \\
+1.50 /+3.00 \times 90 \\
+0.50 /+1.50 \times 90\end{array}$ & $\begin{array}{l}+1.50 /+1.00 \times 180 \\
+2.00 /+1.00 \times 90 \\
+0.50 /+0.50 \times 90\end{array}$ & $\begin{array}{l}3 \\
5 \\
6\end{array}$ & $\begin{array}{l}4 \\
2 \\
1\end{array}$ & $\begin{array}{r}67 \\
6 \\
13\end{array}$ & \\
\hline
\end{tabular}

$\star$ Data unavailable.

with an upper lid lesion and two children with a lower lid lesion. Of the remainder $15(68 \%)$ had significant astigmatism (Fig 1) with only two children with upper lid involvement and five children with lower lid involvement showing no astigmatic error on the side of the haemangioma (Table 3).

In all 15 patients with astigmatism the axis of the plus cylinder was found to be perpendicular to the main axis of the haemangioma (Table 4). Table 4 also indicates the change in astigmatism between the preinjection and postinjection refractions for the 13 children with complete refractive data. In seven of the 13 children $(53.8 \%)$ astigmatism was either eliminated or greatly reduced (by 1.50 dioptres or more). In two children $(15 \cdot 4 \%)$ astigmatism was reduced by 0.50 dioptre, but in four children $(30.8 \%)$ astigmatism remained unchanged despite the fact that three showed a good response to treatment in the first 18 months of life. Three children showed a reduction in astigmatism in the uninvolved eye of 1.50 (two) or 2.00 dioptres (Fig 1).

The spherical equivalents of refractive error for 22 patients prior to treatment are presented in Figure 2. Three patients were found to be myopic on the side of the haemangioma and two on the uninvolved side. Only one patient with myopia was noted to have amblyopia and he was also found to have an asymmetric astigmatic error of +2.50 dioptres cylinder on the side of the haemangioma. This patient had a reduction of myopia following treatment from -0.75 dioptre to +0.25 dioptre. One further patient, who was not amblyopic, had a reduction of myopia from $-1 \cdot 25$ dioptres to -0.50 dioptre following steroid injection. The third patient was unchanged at -0.75 dioptre.

\section{Discussion}

This study confirms that local injections of steroids are a simple method of achieving a high rate of resolution of adnexal haemangiomas. $81 \cdot 5 \%$ of patients ( 22 of 27 ) showed a marked response, the lesion reducing to $25 \%$ or less of its original size. Only two patients showed no response, and this included one girl who was 14 years old at the time of first injection.
The mechanism of action of local steroid is uncertain, though a vasoconstrictor effect is thought to be most likely. Zweifach et $a l^{16}$ have shown that the terminal vascular bed is rendered sensitive to the vasoactive drugs by steroids, suggesting that the vessels in the haemangioma may be sensitised to naturally occurring vasoactive amines by local steroid injections. This would imply that steroids are simply accelerating the natural involutional process.

Only two of the lesions in this series were examined by biopsy and it is therefore difficult to comment on the relative response of either the capillary or the cavernous portion of the haemangioma (the classification being based

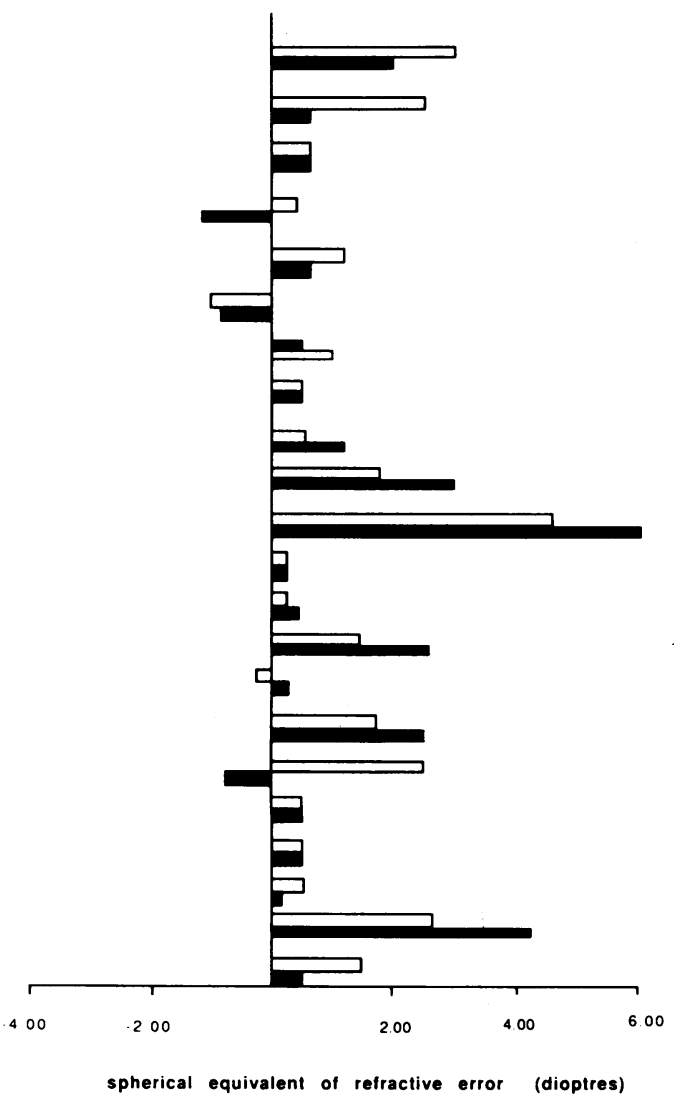

Figure 2 The spherical equivalent of refractive error in patients with an adnexal haemangioma. White bars: uninvolved eye. Black bars: eye with haemangioma. 
on the calibre of the predominant vascular channels present in the harmartoma ${ }^{17}$ ). In previous reports only the haemangioendothelioma has been thought to be less responsive to treatment, "and this may explain why the two children in this series failed to respond.

This study lends support to the view that loss of visual function in these children is usually the result of induced refractive change, rather than obstruction of the visual axis or strabismus.

Anisometropia was present in $68 \%$ of children (15 of 22) with adnexal haemangiomas. We did not find myopia to be a common refractive error, but did note a high incidence of asymmetric astigmatic errors. Upper lid lesions carried a high risk of astigmatism, with only two out of 14 patients showing no such error. Lower lid lesions were less likely to lead to astigmatism, though this was not invariable with one haemangioma leading to 2.00 dioptres of astigmatism. In every case the axis of astigmatism (plus convention) was found to point towards the haemangioma.

Similar findings have been reported with haemangiomas by Robb' and for varied adnexal masses by Bogan et al ${ }^{18}$ Robb concluded on the basis of keratometry readings that the astigmatic component of the refractive error originated in the cornea. It is known that the maximum rate of change in the corneal radius of curvature following birth occurs in the first year of life. ${ }^{19} \mathrm{~A}$ difference of less than $0.1 \mathrm{~mm}$ between the principal radii of curvature of the cornea will cause an astigmatism of 0.50 dioptre. It would therefore seem possible that the refractive error associated with haemangiomas, which appear within the first two months of life, is induced by pressure of the lesion leading to a mechanical distortion of the cornea.

Studies of children with normal eyes by techniques of near retinoscopy, ${ }^{20}$ cycloplegic retinoscopy, ${ }^{21}$ and photorefraction ${ }^{22}$ have demonstrated a higher incidence of astigmatism in infants than adults. The predominant axis of the positive cylinder remains controversial, ${ }^{21} 23$ though there is agreement that the astigmatism decreases and has largely disappeared by school age (4 to $5 \frac{1}{2}$ years of age). The possibility that the astigmatic errors we have recorded reflect the normal astigmatism of infancy is small, because in each case the axis of astigmatism was related to the location of the haemangioma.

In contrast to the studies on normal infant eyes in which astigmatism was shown to decrease over the first five years. of life Robb ${ }^{7}$ found that astigmatism associated with haemangiomas persisted despite resolution of the lesion. Only two out of 16 patients lost astigmatism during observation - one at 1 year of age and one at 8 years of age. Astigmatism persisted in 11 beyond 6 years and in six beyond 12 years. He concluded that a permanent corneal change had resulted from the presence of the haemangioma. A review of 14 children seen in this unit before the introduction of steroid injection has also shown this failure of the astigmatism to disappear spontaneously in children with haemangiomas (unpublished data).

In those of our children who had an astigmatic error and responded to treatment with local steroids, we noted a marked reduction of astigmatism in $53.8 \%$ (seven of 13), a lesser reduction in $15 \cdot 4 \%$ (two of 13 ), and no reduction in $30.8 \%$ (four of 13 ). These results may in fact simply reflect a return to the rate of spontaneous reduction in astigmatism that might be expected in unaffected children, though greatly exceeding the rate of reduction seen with untreated haemangiomas. It cannot, however, be argued that successful treatment of the haemangioma removes the risk of amblyopia and therefore regular refraction and visual assessment remain necessary.

No serious complications were seen in this study. Reported complications, however, include eyelid necrosis, ${ }^{24}$ permanent subcutaneous fat atrophy, ${ }^{25}$ and central retinal artery occlusion $^{26}$ - presumed to be due to retrograde arterial flow leading to embolism of steroid suspension in the central retinal artery. We believe these risks can be minimised by accurate injection technique at multiple sites in the lesion, taking care to avoid direct injection into the vascular channels by drawing back on the syringe before injection. In addition the potential for adrenal suppression and the risks of a general anaesthetic exist. Although the dosages used might potentially lead to transient suppression of cortisol levels, ${ }^{27}$ the half life of the steroid regimen used is less than 30 hours and we observed no major systemic effects. We found only one case of subcutaneous fat atrophy which resolved over a period of six months.

\section{Conclusion}

Intralesional injection of steroids is an effective way of managing haemangiomas in children. Most respond to one or two injections within a period of two to four months and achieve a satisfactory resolution of the lesion. In view of the high incidence of visual disability associated with vascular hamartomas and the possibility that treatment may have a role in reversing the high rate of induced astigmatism found, we would suggest treatment is carried out at an early stage for any lesion thought likely to lead to anisometropia, strabismus, or lid closure. Particular attention should be paid to children with a haemangioma of the upper lid, and followup refraction and visual assessment are essential.

1 Jacobs AH, Walton RG. The incidence of birthmarks in the neonate. Pediatrics 1976; 58: 218-22.

2 Bivings L. Spontaneous regression of angiomas in children. f Pediatr 1954; 45: 643-7.

3 Bowers RE, Graham EA, Tomlinson KA. The natural history of the strawberry naevus. Arch Dermatol 1960; 82: 667-80.

4 Haik BG, Jakobiec FA, Ellsworth RM, Jones IS. Capillary hemangioma of the lids and orbit: an analysis of the clinical features and therapeutic results in 101 cases. Ophthalmology 1979; 86: 760-89.

5 Stigmar G, Crawford JS, Ward CM, Thompson HG. Ophthalmic sequelae of hemangiomas of the eyelids and orbit. Am $\mathcal{F}$ Ophthalmol 1978; 85: 806-13.

6 Deady JP, Willshaw HE. Vascular hamartomas in childhood. Trans Ophthalmol Soc UK 1986; 105: 712-6.

7 Robb RM. Refractive errors associated with hemangiomas of the eyelids in infancy. Am $\mathcal{F}$ Ophthalmol 1977; 83: 52-8.

8 Henderson JS. Orbital tumors. Philadelphia: Saunders, 1973: 139.

9 Kushner BJ. Local steroid therapy in adnexal hemangioma. Ann Ophthalmol 1979; 11: 1005-9.

10 Zak AT, Morin DJ. Early local steroid therapy of infantile eyelid hemangiomas (local steroid therapy of eyelid hemangiomas). F Paediatr Ophthalmol Strabismus 1981; 18: 25-7.

11 Kushner BJ. Intralesional corticosteroid injection of infantile adnexal hemangioma. Am. F Ophthalmol 1982; 93: 496-506. 
12 Willshaw HE, Deady JP. Vascular hamartomas in childhood. f Pediatr Surg 1987; 22: 281-3.

13 Kushner BJ. The treatment of periorbital infantile hemangioma with intralesional corticosteroid. Plast Reconsir Surg 1985; 76: 517-24.

14 Fielder AR, Moseley MJ. Do we need to measure the vision of children. $7 R$ Soc Med 1988; 81 : 380-3.

15 Jampolsky A. In: Crawford JS, Flynn JT, Haik BG, et al, eds. Pediatric ophthalmology and strabismus. Trans New Orleans Acad Ophthalmol New York: Raven, 1981: 441-2.

16 Zweifach BW, Shore E, Black MM. The influence of the adrenal cortex on behaviour of the terminal vascular bed. ann NY Acad $S$ ci 1953;56:626-33.

7 Rooke Rooke A, Wilkinson DS, Ebling FJG. Textbook of dermatology

18 Bogan S, Simon JW, Krohel GB, Nelson LB. Astigmatism associated with adnexal masses in infancy. Arch Ophthalmo 1987; 105: 1368-70.

19 Weale RA. A biography of the eye. London: Lewis, 1982: 103.

20 Gwaizda J, Scheiman M, Mohindra I, Held R. Astigmatism in children: changes in axis and amount from birth to six years. Invest Ophthalmol Vis Sci 1984; 25: 88-92.
21 Dobson V, Fulton AB, Sebris SL. Cycloplegic refractions of infants and young children: the axis of astigmatism. Invest Ophthalmol Vis Sci 1984; 25: 83-7.

22 Howland HC, Sayles N. Photorefractive measurements of astigmatism in infants and young children. Invest Ophthalmol Vis Sci 1984; 25: 93-102.

23 Fischer FP. In: Sorsby A, ed. Modern trends in ophthalmology. London: Butterworth, 1984; 2: 84 .

24 Vasquez-Botet R, Reyes BA, Vasquet-Botet M. Scleroder miform linear atrophy after the use of intralesional steroids or periorbital hemanagiomas: a review of complications. f Pediatr Ophthalmol Strabismus 1989; 26: 124-7.

25 Droste PJ, Ellis FD, Sondhi N, Helveston EM. Linear subcutaneous fat atrophy after corticosteroid injection for capillary hemangioma. Am $\mathcal{F}$ Ophthalmol 1988; 105: 65-9.

26 Shorr N, Seiff SR. Central retinal artery occlusion associated with periocular injection for juvenile hemangioma. Ophthalmic Surg 1986; 17: 229-31.

27 Sutula FC, Golver AT. Eyelid necrosis following intralesiona corticosteroid injection for capillary hemangioma. Ophthalmic Surg 1977; 18: 103-5. 